artige Institutionen im Jagdverband vertreten hat. So gehört Dr. SChramm zu den herausragenden Vertretern des Jagdverbandes, die sich im hohen Maße um die jagdliche Forschung verdient gemacht haben. Dafür soll auch an dieser Stelle herzlicher Dank abgestattet werden, verbunden mit dem Wunsch für ein recht langes weiteres Wirken für die Natur, die Jagd und speziell die Jagdwissenschaft.

E. UECKERMANN

\title{
Professor Alessandro Ghigi †
}

Der emeritierte Professor der Universität Bologna, Alessandro Ghigi, ist in Bologna, wo er 1875 geboren wurde, am 20. November 1970 gestorben.

Sein ganzes Leben widmete er bis in sein hohes Alter dem Studium, der Forschung und der Lehre auf dem Gebiete der Zoologie, insbesondere der Säugetierkunde und der Ornithologie. Die besondere Liebe galt den Hühnervögeln, er war ein begeisterter Züchter vieler Fasanenarten.

Die wissenschaftliche Laufbahn führte ihn von Bologna über Ferrara wieder in seine Heimatstadt zurück, in der er den Lehrstuhl für Zoologie übernahm und viele Jahre Rektor der Universität war. Zahlreiche zoologische Exkursionen und Forschungsreisen führ-

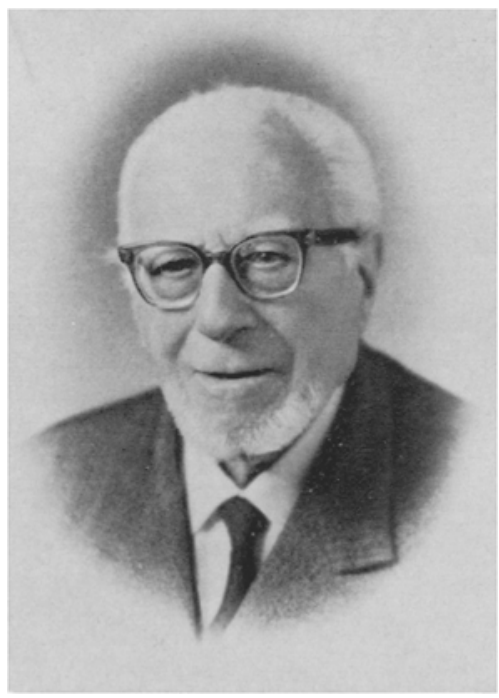
ten ihn in ferne Länder, in denen er Material sammelte, darunter auch für die Wissenschaft neue Tierarten. Im Jahre 1931 gründete er das Laboratorium für Angewandte Jagdzoologie, das von ihm bis 1950 geleitet wurde und dessen Arbeiten u. a. Unterlagen für die italienische Jagdgesetzgebung erarbeiten sollten, mit der er sich seit 1910 beschäftigt hatte. Viele der Schutzmaßnahmen, die in die italienischen Jagdgesetze von 1931,1939 und 1967 aufgenommen wurden, sind ihm zuzuschreiben. Von seiner wissenschałtlichen Tätigkeit zeugen ungefähr 350 Veröffentlichungen, in denen viele bedeutungsvoll für die Systematik, die Genetik, die Ökologie und insbesondere für die Säugetier- und Vogelkunde sind.

Als langjähriger Präsident der italienischen Sektion des Internationalen Rates für Vogelschutz beschäftigte er sich mit der Gründung von

Faunenschutzgebieten in Italien. Um sein Andenken als Präsident der Kommission für Naturschutz des Nationalen Forschungsrates zu ehren, wird in Bologna ein Institut für Natur- und Vogelschutz gegründet werden. Über die Grenzen seines Vaterlandes hinaus vertrat er sein Arbeitsgebiet als Präsident und Ehrenmitglied der italienischen Delegation im Conseil International de la Chasse und als häufger Teilnehmer an den Kongressen des Internationalen Ringes der Jagdwissenschaftler.

Zwei Ehrendoktorwürden und zahlreiche Ehrenmitgliedschaften in wissenschaftlichen Organisationen zeugen von der weltweiten Anerkennung seines Wirkens.

Der Tod von Alessandro Ghigr hinterläßt eine unausgefüllte Lücke und bedeuter einen schweren Verlust für alle, die an Naturschutz und Jagdwissenschaft interessiert sind.

A. ToschI 